\title{
Exogenous plant growth regulator and foliar fertilizers for phytoextraction of cadmium with Boehmeria nivea [L.] Gaudich from contaminated field soil.
}

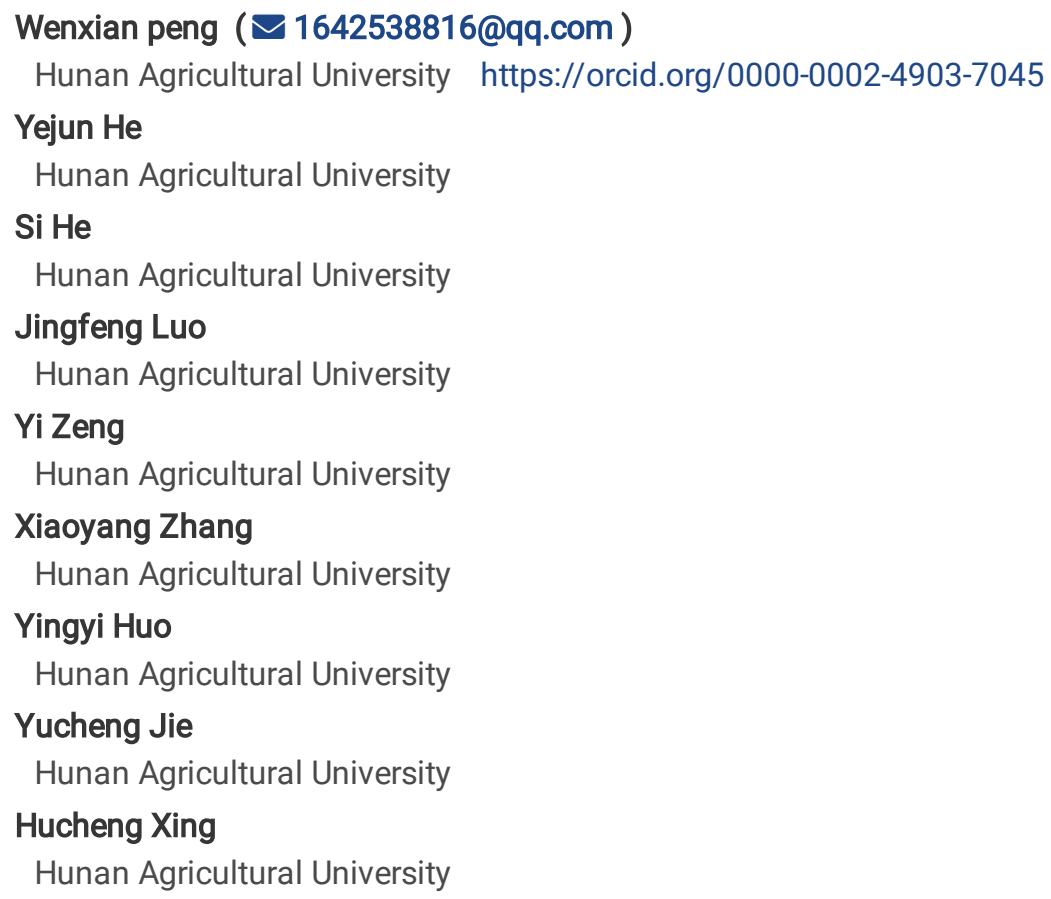

\section{Research Article}

Keywords: Ramie, plant growth regulator, Fertilizer, Cadmium, Gibberellin, Phytoextraction

Posted Date: February 25th, 2022

DOI: https://doi.org/10.21203/rs.3.rs-1197456/v1

License: (1) This work is licensed under a Creative Commons Attribution 4.0 International License. Read Full License 


\section{Abstract}

(1) Background: As a enrichment plant, ramie can be used for the phytoremediation of cadmium (Cd)-contaminated soil. However, it is worth exploring the role of plant growth regulators and foliar fertilizers in the process of plant growth and development and Cd adsorption.

(2) Methods: By measuring the agronomic traits, Cd content of aboveground and underground ramie, calculating the Cd transfer coefficient (TF) and Cd bioconcentration factors (BCF), and the correlation between various indicators. This study examined the effects of plant growth regulators and foliar fertilizers on ramie's capacity for $\mathrm{Cd}$ accumulation and transportation,

(3) Results: Plant growth regulators and foliar fertilizers increased the $\mathrm{Cd}$ content of the aboveground ramie, reduced the Cd content of the underground ramie, and increased the TF. Among them, GA-1 increased the Cd content of the aboveground ramie to 3 times more than that of the control and reduced the $\mathrm{Cd}$ content of the underground ramie by $54.76 \%$. Salicylic acid (SA) increased the Cd content of the aboveground ramie to 3 times more than that of the control. The combination of GA and foliar fertilizer reduced the Cd content of the aboveground and underground ramie and the TF and BCF of the underground ramie. After the hormones were sprayed, the TF of ramie had a significant positive correlation with the Cd content of the aboveground ramie; the BCF of the aboveground ramie had a significant positive correlation with the Cd content and TF of the aboveground ramie.

(4) Conclusions: The results indicate that Brassinolide (BR), gibberellin (GA), ethephon (ETH), polyamines (PAs), and salicylic acid (SA) have different effects on the enrichment and transport of $\mathrm{Cd}$ in ramie. This study provided an effective method to improve the capacity for ramie to adsorb heavy metals during cultivation.

\section{Introduction}

With the advances in urbanization and industrialization, heavy metal pollution in China has become a serious problem. (Cai et al. 2019, Huang et al. 2017b, Zeng et al. 2017) According to a 2014 survey of soil pollution in China, $16.1 \%$ of the country's soil contamination exceeded the legal limit, with heavy metal pollution contributing the most (82\%). Cadmium (Cd) is a nonbiological essential heavy metal and one of the most toxic components of heavy metal pollution.(Koleli et al. 2004) Approximately $20 \%$ of total cultivated lands were contaminated with Cd in China.(Xue et al. 2014) Because of its similar chemical structure to zinc, Cadmium is easily absorbed by plants and can cause serious toxicity to plants, animals and humans even at low concentrations (Malandrino et al. 2011) Cadmium in soil can reduce plant growth, biomass, crop yield, and quality in plant(Ramzani et al. 2016) The ecotoxicity of Cadmium is relatively large, and the impact on the environment and the population health is more worthy of attention and the increasing population and decreasing farmland area seriously threaten the security of food, fiber, and so on. Hence, remediate and reuse the Cd-polluted lands is becoming more and more necessary and urgent. And there is a critical need to develop efficient techniques to remediate soil contaminated with $\mathrm{Cd}$.

Phytoremediation is a method of remediation that considers both ecological and economic effects and is a green technology developed for its strong potential to remove environmental pollution. (Huang et al. 2017a, Yang \&Shen 2020, Zhu et al. 2020) It is often used in large-scale decontamination projects and has attracted considerable attention in recent years(Liang et al. 2021) Phytoremediation can mainly be categorized into phytostabilization, photoevaporation, and phytoextraction according to the uptake mechanisms. Phytoextraction is considered more effective because it can permanently remove metals from contaminated sites. The repair ability of this plant depends not only on its biomass, but also on its absorptive capacity(Zhao et al. 2021). Ramie (Boehmeria nivea [L.] Gaudich.) is a highly adaptable herbaceous perennial root that has been cultivated for more than 2000 years in China.(Tang et al. 2015b) Its fast growth, high fecundity, and high biological yield(Ali \&Hadi 2015) make up for the deficiencies of other hyperaccumulators, such as Sedum alfredii (Tao et al. 2020) and sunflowers(Zamani et al. 2020). Research has demonstrated that ramie can remove a fair amount of metal from the soils due to its stronger root system, faster growth rate, and higher biomass(Yang et al. 2010). Ramie is commonly used for its fiber, its products do not enter the food chain, and it is not associated with any health risk. Researchers have also modified varieties of ramie at the genetic level to improve its tolerance and ability to accumulate heavy metals. (Zhu et al. 2020) Moreover, ramie is a permanent crop that provides ecological and economic benefits to cultivation measures, and the cost of restoration can be recovered by ending continuous cropping. Therefore, ramie, the ideal phytoremediation material for $\mathrm{Cd}-$ contaminated soil, has great potential for use in the control of Cd pollution. 
To obtain high removal efficiencies, lots of regulators including chelating agents and plant growth regulators have been used to improve the bioavailability of metals in soil and shoot biomass, respectively.(Hasan et al. 2019) (Rostami \&Azhdarpoor 2019) Plant growth regulators play a crucial role in the regulation of plant growth and development and in the response to external stresses. (Santner \&Estelle 2009) The main plant growth regulator are auxin, gibberellin (GA), cytokinin, abscisic acid, ethylene (ETH), and Brassinolide (BR) as well as some recently identified plant regulator, including polyamines (PAs) and salicylic acid (SA). GA has been proven to enhance the resistance of plants to heavy metal stress and to promote the accumulation of heavy metals. Masood found that $10 \mathrm{~mol} \mathrm{~L}^{-1} \mathrm{GA}$ can reverse the adverse effects of $\mathrm{Cd}$ on brassica.(Masood et al. 2016) The $10^{-6} \mathrm{~mol} \mathrm{~L}^{-1} \mathrm{GA}_{3}$ treatment increased Cd accumulation by $289 \%$ and the bioaccumulation coefficient by $128 \%$ in parthenium.(Ali \&Hadi 2015) ETH is mainly used as a ripening agent in practical applications, but several studies have demonstrated that ETH plays a vital role in Cd stress. The tolerance of drupe to $\mathrm{Cd}$ can be increased by maintaining an appropriate level of ETH and a low ETH sensitivity through an antioxidant defense mechanism.(Wang et al. 2020) SA can reduce the accumulation of Cd in the aboveground part of rice.(Wang et al. 2021a) SA can enable plants to resist abiotic stresses, such as ultraviolet radiation, low temperatures, heat shock, water deficit, salt injury, and heavy metals, and plays a role in the cross-protection response of plants to abiotic stresses.(Madany et al. 2020, Yadav et al. 2020) SA can also increase mineral nutrition in plant organs and regulate the photosynthesis system, improving overall crop quality. (Kou et al. 2021, Sharma et al. 2020, Yalpani \&Raskin 1993) BR is a new plant hormone involved in plant growth and stress response and has been reported to promote plant growth, improve photosynthesis, and reduce heavy metal toxicity in plants.(Guo et al. 2018, Li et al. 2012)

PAs are compounds containing two or more amino groups. The raw materials used in its synthesis are ornithine and arginine. PAs play a crucial role in promoting the absorption of inorganic ions by roots, which improves resistance to stress and osmotic stress. (Pal et al. 2019) Binding PAs may play an essential role in resistance to $\mathrm{Cu}^{2+}$ stress. (Zhao et al. 2008) Therefore, plant growth regulators can improve shoot biomass and enhance their accumulation capacity for heavy metals in aboveground plant parts. However, no effect of plant growth regulators has been observed on the enrichment and transport of heavy metals in ramie.

Foliar fertilizer is a key source of nutrient elements for plant growth and development. Foliar fertilizer can also improve plants' resistance to stress, promote plant growth and development, and increase yield. Potassium and phosphorous are the key elements for plant growth. Potassium activates many types of enzymes, which can enhance photosynthesis and the synthesis and metabolism of carbohydrates. (Zhao et al. 2020) The use of potassium fertilizer during production can increase the yield and stress resistance of crops. Phosphorus is a key component of nucleic acid, nucleoproteins, phospholipids, and enzymes. The use of phosphorus fertilizer during production can enhance the crops' resistance against drought and cold.(Atafar et al. 2010) However, few studies have investigated the effects of fertilizers on the growth and ability of ramie to accumulate and transport Cd.

The above studies have shown that GA can improve the biomass of plants and increase plant cadmium accumulation. The foliar fertilizer can provide the nutrient elements $\mathrm{N}, \mathrm{P}, \mathrm{K}$, which are necessary for plant growth, so as to improve stress resistance of plant. However, their activity depends on the concentration of their use, the environmental factors that affect their absorption, and the physiological state of the plant(Rostami \&Azhdarpoor 2019). It is unknown whether supplementation of nutrient elements $N, P, K$ can better improve the biomass and enrichment capacity of $\mathrm{Cd}$ in ramie when $\mathrm{GA}$ is applied. And the effects of $\mathrm{GA}$ alone or in combination with $\mathrm{KH}_{2} \mathrm{PO}_{4}$ or $\mathrm{KNO}_{3}$ on the phytoextraction efficiency of ramie were unclear.

In this study, two field experiment were conducted, one was using GA, ETH, SA, PAs, and BR foliar spray of ramie and another was using $\mathrm{GA}$ with $\mathrm{KH}_{2} \mathrm{PO}_{4}$ or $\mathrm{KNO}_{3}$ addition to $\mathrm{Cd}$ contaminated soils aimed to (1) investigate the treatment influence on Cd contents, translocation and accumulation in plant; and (2) estimate the treatment effects on the agronomic traits of ramie. These results will be helpful to compare the effects of different plant growth regulators and $\mathrm{GA}$ in combination with $\mathrm{KH}_{2} \mathrm{PO}_{4}$ or $\mathrm{KNO}_{3}$ as potential amendments for enhancing Cd phytoextraction by ramie.

\section{Materials And Methods}

\subsection{Plant materials and soil sample}

Ramie is an asexual perennial plant propagated by using cuttings of lateral branches of approximately $15 \mathrm{~cm}$ in length. Ramie for Experiment $A$ and Experiment $B$ were arranged in two completely randomized plots with three replicates. Each plot contained six plants, planted in rows spaced $0.5 \mathrm{~m}$ apart, with a distance of $0.4 \mathrm{~m}$ between plants within rows. Experiment $\mathrm{A}$ : Ramie was planted in a Cdpolluted farmland in Hunan Agricultural University's training base, Changsha City, Hunan Province, China. Experiment B: Ramie was planted in a Cd-polluted farmland in Liu yang City, Hunan Province, China. The lateral branches of ramie variety 171 were cut and 
propagated in June 2017. The plants were planted in the field in April 2017 and were mowed in December 2017. The ramie variety 171 was provided by the Ramie Research Institute of Hunan Agricultural University (Changsha, China).

Surface soil samples $(0-20 \mathrm{~cm})$ were taken from the test site, Then, the soil samples were air-dried and sieved through a 2-mm nylon screen to remove any debris before testing. Six air-dried soil samples were randomly taken to determine the physical-chemical properties. (GB15618-2018) The soil type was red soil, $\mathrm{pH}=5.73$, the average $\mathrm{Cd}$ content in soil was $3.27 \mathrm{mg} \mathrm{kg}^{-1}$, soil organic matter= $29.25 \mathrm{~g} \mathrm{~kg}^{-1}$, total nitrogen $=1.56 \mathrm{~g} \mathrm{~kg}^{-1}$, total phosphorus $=0.51 \mathrm{~g} \mathrm{~kg}^{-1}$, total potassium $=14.71 \mathrm{~g} \mathrm{~kg}^{-1} \mathrm{\square}$

\subsection{Field experiment}

Experiment A and Experiment B were conducted at vigorous growing period. In experiment A, five plant growth regulators in different concentrations were sprayed into the positive and negative sides of ramie leaves in the corresponding plots. (Table 1) In experiment $\mathrm{B}$, $\mathrm{GA}, \mathrm{KNO}_{3}$ and $\mathrm{KH}_{2} \mathrm{PO}_{4}$ are compounded in different concentrations was sprayed onto the positive and negative sides of ramie leaves in the corresponding plots. (Table 2) This procedure was repeated five times, once every 15 days, from April 19, 2018. To reduce the effect of direct sunlight and to prevent the agents from being washed away by the rain, the agents were administered on sunny mornings when the sun is not too strong.

The ramie grew in the soil for 125 days after transplantation and then harvested and divided into various parts for further processing. Before ramie was harvested, the agronomic traits of the ramie under each treatment were examined during the mature stage. A total of 10 plants were selected for measurement. A meter scale was used to measure the height of the plants. The diameter and thickness of the stems were measured using a micrometer. Ramet number was measured through manual calculation. The area of the leaves was calculated by measuring their length and width with a straightedge. The tissues were carefully washed with tap water and doubledistilled water to ensure no dust or other undesirable materials remained on the surface of the samples. The tissues were dried in an oven at $60 \pm 5{ }^{\circ} \mathrm{C}$ for 4 days to ensure the constant weight. The weight of the samples was then measured, and the samples were crushed into powder for the $\mathrm{Cd}$ analysis.

Take the soil in the rhizosphere of ramie囚and then the soil samples were air dried, crushed gently, and passed through a 2-mm sieve prior to the $\mathrm{Cd}$ analysis for calculation of index.

\subsection{Determination of Cd concentration}

The dried plant materials and soil samples were ground into powder and sieved, and $0.5 \mathrm{~g}$ samples were digested in mixed acid $\left(\mathrm{HNO}_{3}\right.$ $\left.+\mathrm{HClO}_{4}[3: 1, \mathrm{v} / \mathrm{v}]\right)$. (Tang et al. 2015a) Cd content was determined using an atomic absorption spectrometer (SOLAAR M6). The linear fitting of the results of the samples measurements was 0.998 and the fitting degree of the equation was tested by chi square.

\subsection{Statistical analysis}

2.4.1 Comparison of Ramie Field Performance with different treatments

Field performance among different treatments were compared using ANOVA (analysis of variance) in SAS 9.4 software (SAS Institute, Cary, NC, United States). Plant data with different treatments were considered independent variables. The mean of each trait was tested at the $p<0.05$ level and $p<0.01$ level using Duncan's multiple range test. (The following is the same) Evaluation of the overall field performance is a multi-criteria decision-making process that involves many factors.

In this study, a Membership function (MF) value and synthetic membership function (SMF) value were used to comprehensively express overall field performance. (Jin et al. 2020)The MF value of each field performance trait was calculated based on the following formula:

$$
y i(k)=[x i(k)-\min x(k)] /[\max x(k)-\min x(k)](1)
$$

Where $y i(\mathrm{k})$ represents the MF value of the $\mathrm{k}$ th field performance trait, $x i(k)$ denotes the field-recorded value of the kth field performance, and $\max x(k)$ and $\min x(k)$ represent the largest and smallest value of $x i(k)$, respectively.

The SMF value of each treatment was calculated based on the following formula: 


$$
\sum_{i=1}^{\mathrm{i}=\mathrm{n}} y i(k)=[x i(k)-\min x(k)] /[\max x(k)-\min x(k)(2)
$$

2.4.2 Comparison of cadmium related indexes of Ramie with different treatments

The accumulation and absorption of cadmium in Ramie with different treatments can be shown by many indexes. (Wei et al. 2012) The (BCF) value of each treatment was calculated based on the following formula:

$$
y B C F(k)=x p a r t o f p l a n t(k) / x \operatorname{soil}(k)(3)
$$

Where $y B C F(k)$ the $C d$ bioconcentration factor value (BCF) of the $k$ th treatments, $x$ part of plant $(k)$ denotes the cadmium concentration value of the $k$ th, and $x$ soil $(k)$ represent the cadmium concentration value of the $k$ th soil.

The Cd transfer coefficient (TF) value of each treatment was calculated based on the following formula:

$$
y T F(k)=x \text { aboveground }(k) / x u n d e r g r o u n d(k)(4)
$$

Where $y \operatorname{TF}(k)$ represents the Cd transfer coefficient value (TF) of the $k$ th treatments, $x$ aboveground denotes the cadmium concentration value of the $k$ th aboveground, and $x$ underground $(k)$ represent the cadmium concentration value of the $k$ th soil.

The Enrichment quantity value of each treatment was calculated based on the following formula:

$$
y E Q(k)=x \text { biomass }(k) * x \text { Cdcontent(aboveground }+ \text { underground })(k)(5)
$$

Where $y E Q(k)$ represents the enrichment quantity value of the $k$ th treatments, $x$ biomass $(k)$ denotes the biomass of the $k$ th treatments, and $x \mathrm{Cd}$ content (aboveground +underground) ( $k$ ) represent the $k$ th $\mathrm{Cd}$ content of the sum of aboveground and underground.

\subsubsection{Correlation between cadmium related indexes and agronomic traits of ramie in different treatments}

Correlation analysis (CA analysis) was used to evaluate the relationship between the growth and development of ramie and the accumulation and absorption of $\mathrm{Cd}$. Correlations between the ramie's overall agronomic traits and the cadmium related indexes were performed using the CORR procedure in SAS 9.4 software. Pearson's correlation coefficients and their significance were used to assess the strength of the correlations.

All assays were made in triplicate. Graphs were drawn using GraphPad Prism 7.0 (GraphPad Software, San Diego, CA, USA).

\section{Results}

\subsection{Analysis of agronomic traits and enrichment quantity after plant growth regulator treatment and mixture of GA and foliar fertilizers}

\subsubsection{Effects of plant growth regulators on agronomic traits and Cd enrichment}

The effects of plant growth regulator on the agronomic traits were evident. Plant growth varied in accordance with variety and concentration of plant growth regulators. Plant height, stem diameter, skin thickness, and leaf area were the main parameters influencing biomass. As shown in Table 3, GA-3 and PAs-3 treatments significantly increased plant height. For all treatments, plant height significantly decreased after plants were sprayed with ETH. All hormone treatments except the ETH treatments caused significant increases in biomass accumulation compared with the control 1(CK-1) treatment. The effect of plant growth regulators treatments on the leaf area, stem diameter, and skin thickness of ramie was negligible; the ETH-3 treatment was the only treatment to significantly reduce these measures in comparison with control.

Cd enrichment is the overall capacity of ramie to adsorb Cd. Treatment with PAs achieved the most noticeable effect on Cd enrichment; Cd enrichment after treatment with all three concentrations of PAs was significantly higher than after CK-1 treatment. Cd enrichment after treatment with SA-1 and SA-3 was significantly higher than that after CK-1 treatment. The BR-1 and GA-2 treatments also increased Cd enrichment. However, Cd enrichment after the ETH-1, ETH-2, ETH-3 treatments was lower than that after CK-1 treatment.

\subsubsection{Effects of GA and foliar fertilizer mixture on agronomic traits and Cd enrichment}


The GP and GN treatments positively affected the agronomic traits and Cd enrichment of ramie (Table 4). Plant height and biomass of ramie under GP-2, GP-3 and GN-2, GN-3 treatments were generally significantly higher than those under CK-2, but GP-1 and GN-1 treatments were significantly lower. Among the GW treatments, $\mathrm{Cd}$ enrichment after the GP-3 and GN-3 treatments was significantly higher than that after CK-2 treatment. The GP-1, GP-2, GP-3 and GN-1, GN-2, GN-3 reduced the biomass and Cd enrichment of ramie more than GW-1, GW-2, GW-3.

\subsection{Effects of plant growth regulators on Cd content, Cd TF, and Cd BCF of ramie}

\subsubsection{Effects of plant growth regulators on Cd content of ramie}

Compared with the control, plant growth regulator treatments significantly increased the Cd content in the aboveground ramie. The Cd content of the aboveground ramie changed in accordance with type and concentration of plant growth regulators (Figure 1.a). The BR, GA, SA, ETH, and PAs plant growth regulator treatments increased the Cd content of the aboveground ramie. According to the results, the $C d$ content after treatments with various concentrations of plant growth regulators, except the BR-1, GA-3, SA-2, and SA-3 treatments, was considerably higher than that of the control group. The GA-1 and SA-1 treatments exerted the strongest effect; Cd content after these treatments was 3 times higher than that after CK-1 treatment. The Cd content of the aboveground ramie in the GA-1, GA-2, GA-3 group and PAs-1, PAs-2, PAs-3 group decreased as the concentration of GA and PAs increased. The Cd content of the aboveground ramie in the ETH-1, ETH-2, ETH-3 group exhibited the opposite effect. The Cd content of the aboveground ramie in the SA1, SA-2, SA-3 group was similar to that of the BR-1, BR-2, BR-3 group; as the concentration of SA and BR increased, the Cd content of the aboveground ramie decreased at first and then increased.

The plant growth regulators affected the $\mathrm{Cd}$ content of both the aboveground and the underground parts of ramie. The Cd content of the underground ramie after all treatments was generally lower than that of the control group (Figure 1.b), especially the Cd content of the groups treated with BR-2 and GA-1, which was $59.45 \%$ and $54.76 \%$ lower than that of the control, respectively. Similarly, the Cd content of the groups treated with GA-3, PAs-1, and PAs-2 was significantly lower than that of the control group. The Cd content of the underground ramie treated with BR decreased when the concentration of BR increased, which was contrary to the trend for the GA and SA treatments. The $\mathrm{Cd}$ content of the underground ramie after the ETH and PAs treatments did not change significantly.

\subsubsection{Effects of plant growth regulators on Cd TF of ramie}

Cd TF refers to the ratio of $\mathrm{Cd}$ content of the aboveground part of ramie to that of the underground part. TF is an index used to evaluate the transportation of $\mathrm{Cd}$ from underground to aboveground parts of plants. Figure 2 shows that the $\mathrm{Cd}$ TF of ramie treated with lant growth regulators significantly increased. The TFs after the ETH-1, ETH-2, ETH-3 group treatment increased with an increasing concentration of ETH. By contrast, the TFs after the GA-1, GA-2, GA-3 group and PA-1, PA-2, PA-3 group treatment decreased as the concentration of the plant growth regulators increased. The TFs after the SA-1, SA-2, SA-3 group treatment decreased at first and then increased with the concentration of SA. The GA-1 treatment was the most effective and significantly stronger than CK-1, which yielded a TF greater than 2 .

\subsubsection{Effects of plant growth regulators on $\mathrm{Cd} B C F$ of ramie}

A mount of heavy metals a plant absorbs and enriches from soil can be used as an indicator of the plant's enrichment ability. The BCF of $\mathrm{Cd}$ is the ratio of the element content in a certain part of the plant to the corresponding element content in the soil. To a certain extent, the BCF of $\mathrm{Cd}$ reflects the degree of difficulty for an element to migrate through the soil-plant system and indicates $\mathrm{Cd}$ enrichment in plants. As shown in Figure 3.a, the Cd BCF of the aboveground ramie after the GA-1, GA-2, GA-3 group, PA-1, PA-2, PA-3 group and SA-1, SA-2, SA-3 group treatments increased with an increase in the concentration of GA, PAs and SA. The Cd BCF of the aboveground ramie after the GA-1, PAs-1, SA-1 treatments and the GA-2 treatment was significantly higher than that of the control. However, the Cd BCF of the aboveground ramie after the SA-3 treatment was significantly lower than that of the control. The Cd BCF of the aboveground ramie after the ETH-1, ETH-2, ETH-3 group treatment increased at first and then decreased, and the Cd BCF of the aboveground ramie after the ETH-2 treatment was significantly higher than that of the CK-1. The Cd BCF of the aboveground ramie after the BR-1, BR-2, BR-3 group treatment exhibited the opposite behavior to that after the ETH-1, ETH-2, ETH-3 group treatment; the Cd $\mathrm{BCF}$ of the aboveground ramie after the BR-2 treatment was significantly lower than that of the CK-1.

The Cd BCF of the underground ramie after all plant growth regulator treatments was generally significantly lower than that after CK-1 treatment. The Cd BCF of the underground ramie after the GA-1 and SA-1, GA-3 and SA-3, PAs-2, and PAs-3 treatments were 
significantly lower than that after CK-1 treatment and did not markedly change after the GA-2, SA-3 and PAs-1 treatments. The changes in the $\mathrm{Cd} B C F$ of the underground ramie upon increasing concentrations of $\mathrm{BR}$ and $\mathrm{ETH}$ were similar to those in the aboveground $\mathrm{Cd}$ BCF (Figure 3.b).

\subsection{Effects of GA and foliar fertilizer mixture on Cd content, Cd TF, and Cd BCF of ramie}

\subsubsection{Effects of GA and foliar fertilizer mixture on Cd content of ramie}

GA significantly increased the Cd content, TF, and BCF of the aboveground ramie (Figure 1-3). Because fertilizers composed of nitrogen and potassium are known to promote the growth and development of ramie, this study examined whether a mixture of nitrogen foliar fertilizer, potassium fertilizer, and GA could enhance the ability of ramie to absorb and enrich Cd. Figure 4.a shows that treatment with a mixture of GA mixed and foliar fertilizers did not significantly affect the $\mathrm{Cd}$ content of the aboveground ramie compared with CK-2 treatment, except the $\mathrm{GN}-1$ treatment, which reduced the $\mathrm{Cd}$ content by $59.88 \%$. The combination of GA and foliar fertilizer significantly reduced the $\mathrm{Cd}$ content of the aboveground ramie in comparison with $\mathrm{GA}$ alone.

The combination of GA and foliar fertilizer did not significantly affect the Cd content of the underground ramie. The Cd content of the underground ramie after the GP-3 and GN-3 treatments was slightly higher than that after CK-2 treatment (Figure 4.b).

\subsubsection{Effects of GA and foliar fertilizer mixture on Cd TF of ramie}

We discovered that unlike GA alone, the mixture of GA and fertilizers reduced the Cd TF of ramie. However, most compound treatments did not significantly affect the Cd TF in comparison with CK-2 treatment; only the GN-1 treatment significantly affected the Cd TF. The Cd TF after the GN-1 treatment was half that after CK-2 treatment (Figure 5).

\subsubsection{Effects of GA and foliar fertilizer mixture on Cd BCF of ramie}

The Cd BCF of the aboveground ramie after the GP-1, GP-2, GP-3 group treatment and GN-1, GN-2, GN-3 group treatment were generally lower than that after the CK-2 and GW-1, GW-2, GW-3 group treatment, and the interaction between GP-1, GP-2, GP-3 group treatment and $\mathrm{GN}-1, \mathrm{GN}-2, \mathrm{GN}-3$ group treatment made the Cd BCF of the aboveground ramie significantly lower than did the GW-1, GW-2, GW-3 group treatment with the same concentration of GA (Figure 6.a).

The Cd BCF of the underground ramie after the GP-1, GP-2, GP-3 group treatment and GN-1, GN-2, GN-3 group treatment were generally higher than that after the GW-1, GW-2, GW-3 group treatment, but were not significantly different from that after CK-2 treatment, except for the GP-3 treatment (Figure 6.b). The Cd BCF of the underground ramie after the GP-2 treatment was not significantly different from that after the GW-2 treatment. Therefore, treatment with GA significantly reduces the Cd BCF of the underground part of ramie, but the mixture of GA of foliar fertilizer can negate this effect.

\subsection{Correlation analysis of traits}

\subsubsection{Effects of plant growth regulators on correlation}

Figure 7 presents a significant correlation among various indicators after plant growth regulators treatment. For example, plant height was significantly correlated with leaf area and biomass. Leaf area and biomass were positively correlated with plant height, with correlation coefficients of 0.74 and 0.85 respectively. A significant positive correlation was observed between leaf area and biomass, with a correlation coefficient of 0.77 . Aboveground Cd content was significantly correlated with Cd TF and aboveground Cd BCF. Cd TF and aboveground $\mathrm{Cd} \mathrm{BCF}$ were positively correlated, with correlation coefficients of 0.82 and 0.84 . A significant negative correlation was observed between soil Cd content, aboveground $\mathrm{Cd} B C F$, and underground $\mathrm{Cd} B C F$, with correlation coefficients of -0.74 and -0.79 , respectively. The correlation coefficient of the significant positive correlation between Cd TF and aboveground Cd BCF was 0.73 . The correlation coefficient of the significant positive correlation between aboveground $\mathrm{Cd}$ BCF and underground $\mathrm{Cd} B C F$ was 0.63 . Cd enrichment had a significant positive correlation with plant height( 0.72$)$,leaf area $(0.68)$, and biomass $(0.88)$.

\subsubsection{Effects of GA and foliar fertilizers mixture on correlation}

Biomass and $\mathrm{Cd}$ enrichments had a significantly positive correlation after treatment with $\mathrm{GA}$ and foliar fertilizer mixtures. (Figure 8) Aboveground Cd content was positively correlated with Cd TF (0.86) and aboveground Cd BCF (0.92) and negatively correlated with underground Cd BCF (-0.85) and underground Cd content (-0.71). A significant negative correlation was observed between soil Cd

Page $7 / 20$ 
content and underground $\mathrm{Cd}$ content, with a correlation coefficient of -0.68 . Cd TF was significantly and positively correlated with aboveground $\mathrm{Cd} B C F$ and negatively correlated with underground $\mathrm{Cd} B C F$, with correlation coefficients of 0.95 and -0.86 , respectively. Cd enrichment had a significant positive correlation with stem diameter (0.66), leaf area (0.71),andbiomass $(0.90)$.

\section{Discussion}

Treating Cd soil pollution is an urgent task, and the phytoremediation technology-based approach can achieve superior results both economically and ecologically.(Wang et al. 2021b) Ramie is a strong candidate and can promote the green revolution. Planting ramie can not only promote the development of the textile industry but also prevent soil pollution from entering the food chain, which would positively affect human health.(Yaseen et al. 2016) Investigation of the physiological and molecular mechanisms of Cd in ramie is crucial to regulating the amount of $\mathrm{Cd}$ moving from soil to plants and repairing soil. For the short-distance transport of $\mathrm{Cd}$ through the roots, phytochelatin secretion and vacuolar partition via ion channels and transporters are the key elements in the absorption, transport, and accumulation of $\mathrm{Cd}$; for long-distance transport, the loading and unloading of phloem is a crucial element in the transport and accumulation of $\mathrm{Cd}$ to ramie plants. The transport and accumulation of $\mathrm{Cd}$ plants also causes physiological responses to $\mathrm{Cd}$ stress in ramie plants, which can manifest as changes in plant growth regulators levels, photosynthesis, water absorption, and mineral element absorption.(Wang et al. 2021c, Yoneyama et al. 2015) This study examined the effects of several plant growth regulators and the combination of fertilizers and GA on ramie. The increases in the Cd TF of ramie after the hormone treatments may be explained by the following: plant growth regulators caused the increases in the number of physiological and biochemical molecules absorbing and carrying $\mathrm{Cd}$ and enhanced the $\mathrm{Cd}$ resistance of ramie, resulting in the $\mathrm{Cd}$ enrichment of the aboveground part of ramie.

GA, ETH, SA, BR, and PAs play a crucial role in alleviating abiotic stress and regulating the growth and development of plants.(Alcazar et al. 2020, Bajguz 2011) According to results of this study, SA, BR, and PA played an essential role in the transportation of Cd in both the aboveground and underground parts of ramie, and the effects of BR and PA were dependent on concentration and ramie part. GA is a plant growth stimulation hormone that regulates several physiological and biochemical processes, promotes growth and development, affects morphogenesis, and plays an essential role in the response to both biotic and abiotic stresses in plants.(Shu et al. 2018, Spence \&Bais 2015) Studies have demonstrated that plant growth regulators such as SA, GA, and indole-3-acetic acid (IAA) can alleviate abiotic stresses.(Hussain et al. 2020, Jia et al. 2021, Saleem et al. 2015, Zhang et al. 2015) For example, the use of GA on leaves can reduce the uptake of nickel by mung bean plants, increase biomass, and promote growth. The importance of GA under abiotic stress has been well documented. This study confirmed that GA can promote the growth of ramie and improve its ability to absorb and enrich Cd. ETH can inhibit the growth of plants, and the results in subsection 3.1 indicated that ETH caused a decrease in biomass and Cd enrichment. Studies on other plants have demonstrated that ETH can promote leaf abscission and plant maturation and inhibit apical dominance but that spraying at certain stages may produce the opposite effects.(Schubert et al. 2019) The height of ramie decreased after ETH was applied, but the tillering and leaf area of ramie did not change significantly. ETH reduces the main components of biomass, thereby leading to a decrease of biomass. The enrichment of $\mathrm{Cd}$ in the plants decreased in accordance with changes in biomass.

$\mathrm{N}, \mathrm{P}$, and $\mathrm{K}$ are vital nutrients for plant growth. The addition of fertilizer to the cultivation process benefits the growth and development of crops. (Xia et al. 2020) The results of this study demonstrated that GA alone or in combination with $\mathrm{KNO}_{3}$ or $\mathrm{KH}_{2} \mathrm{PO}_{4}$ positively influenced the agronomic traits of ramie, indicating that the mixture of $\mathrm{GA}$ and fertilizer with $\mathrm{N}$ or $\mathrm{P}$ exhibited the same effects on the growth and development of ramie as in previous studies. In addition, treatment with GP (including GP-1, GP-2, GP-3) and GN (including $\mathrm{GN}-1, \mathrm{GN}-2, \mathrm{GN}-3$ ) promoted the enrichment of $\mathrm{Cd}$ in ramie. This may be related to the physiological process ramie undergoes during heavy metal stress. A key regulator of plant growth and development, the functional site of GA at the cellular, tissue, and organ level of ramie is unknown.(Ubeda-Tomas et al. 2008) The site of application for GA on ramie can be a subject for future research. $\mathrm{P}+, \mathrm{K}+$, and $\mathrm{Cd}+$ share the same transport pathway in plants. Although treatment with fertilizer promoted the growth and development of the plants, their $\mathrm{Cd}+$ absorption and transport capacity decreased. Phosphates can increase the ionic strength of Cd adsorption.(Yan et al. 2015) Therefore, the decrease caused by GN (including GN-1, GN-2, GN-3)was more apparent than that caused by GP, especially in aboveground Cd content and aboveground BCF. The BCF after the GP (including GP-1, GP-2, GP-3) and GN (including GN-1, GN-2, GN-3) treatments was higher than that after the GW-1, GW-2, GW-3 group treatment, which may be related to the chelation of root exudates.

Plants' response to Cd stress is a complex physiological process involving ion transporters.(Lu et al. 2020) Studies on yeast(Mesquita et al. 2016), Arabidopsis(Zheng et al. 2018), and rice(Pan et al. 2021) have demonstrated that adenosine triphosphate-binding cassette transporters, heavy metal-associated transporters, and natural resistance-associated macrophage protein transporters are

Page $8 / 20$ 
involved in the response to $\mathrm{Cd}$ stress. The results of the study revealed common phenomena among the hormone treatments: the aboveground $\mathrm{Cd}$ content and Cd BCF increased; the underground Cd content and Cd BCF decreased; and the TF increased significantly after all hormone treatments. Traditionally a textile crop, ramie has high cellulose, hemicellulose, and lignin content in the phloem, which establishes the conditions for $\mathrm{Cd}$ accumulation. The pulp inside ramie contains a large number of vessels that can transport $\mathrm{Cd}$

${ }^{+}$. Hormones promote the growth of the aboveground part of ramie, the transport of $\mathrm{Cd}$, and the accumulation of $\mathrm{Cd}$ in the underground part of the plant. Liu (Liu et al. 2021) discovered that high concentrations of endogenous ETH delayed the formation of an ectoblast barrier and promoted the accumulation of $\mathrm{Cd}$ in the root ectoblasts. Studies by Neumann(Neumann 2015) have demonstrated that ETH-mediated responses usually have high genotypic variability and may partially share common pathways under certain nutritional constraints. Although the biomass and Cd enrichment of ramie decreased after the ETH treatment, the Cd content and BCF of the aboveground ramie increased under high TFs.

\section{Conclusions}

Plant growth regulators and foliar fertilizers increased the Cd content of the aboveground ramie, reduced the Cd content of the underground ramie, and increased the TF. Among them, GA-1 increased the Cd content of the aboveground ramie to 3 times more than that of the control and reduced the Cd content of the underground ramie by $54.76 \%$. Salicylic acid (SA) increased the Cd content of the aboveground ramie to 3 times more than that of the control. The combination of GA and foliar fertilizer reduced the Cd content of the aboveground and underground ramie and the TF and BCF of the underground ramie. After the hormones were sprayed, the TF of ramie had a significant positive correlation with the Cd content of the aboveground ramie; the BCF of the aboveground ramie had a significant positive correlation with the $\mathrm{Cd}$ content and TF of the aboveground ramie. In actual production, the proper concentration of PAs, GA, SA and BR can be sprayed during the prosperous period of ramie, which will increase the biomass of ramie and increase the efficiency of cadmium enrichment of ramie. It is generally not recommended to mix plant regulators and foliar fertilizers.

\section{Declarations}

Availability of data and materials: All data generated or analyzed during this study are included in this published article.

Funding: This research was funded by Key R \& D Program of Hunan Province, grant number 2022NK2017.

\section{Author information}

\section{Affiliations}

Ramie Research Institute (Hunan Agricultural University), Changsha, 410128, China

Key Laboratory of germplasm resources innovation and utilization, Changsha, 410128, China

Wenxian Peng, Yejun He, Si He, Jinfeng Luo, Yi Zeng, Xiaoyang Zhang, Yingyi Huo, Yucheng Jie, Hucheng Xing

Authors Contributions: Conceptualization, Wenxian.Peng. and Yejun.He.; methodology, Hucheng. Xing.; software, Wenxian. Peng. and Yejun.He.; validation, Wenxian.Peng.; investigation, Xiaoyang. Zhang.; resources, Yucheng. Jie.; data curation, Jinfeng. Luo. and Yi. Zeng.; writing-original draft preparation, Wenxian.Peng.; writing-review and editing, Wenxian.Peng., Si.He. and Yingyi.Huo. ; visualization, Wenxian.Peng.; supervision, Hucheng. Xing.; project administration, Hucheng. Xing.; funding acquisition, Hucheng. Xing. All authors have read and agreed to the published version of the manuscript.

\section{Corresponding author}

Correspondence to Hucheng Xing

\section{Ethics declarations}

Ethics approval: The manuscripts reporting studies are not applicable for human participants, human data, or human tissue. The manuscript does not contain any individual person's data in any form.

Consent to participate: Not applicable. 
Consent to Publish $₫$ All authors agree to publish.

Competing interests $\$ The authors declare that they have no known competing financial interests or personal relationships that could have appeared to influence the work reported in this paper.

Acknowledgements: Many thanks to the editor and reviewers for telling us how to make the manuscript more completed and better. Thanks to Hunan Agricultural University for providing the environment for the successful completion of this work.

\section{References}

1. Alcazar R, Bueno M, Tiburcio AF (2020) : Polyamines: Small Amines with Large Effects on Plant Abiotic Stress Tolerance. Cells 9

2. Ali N, Hadi F (2015) Phytoremediation of cadmium improved with the high production of endogenous phenolics and free proline contents in Parthenium hysterophorus plant treated exogenously with plant growth regulator and chelating agent. Environ Sci Pollut Res Int 22:13305-13318

3. Atafar Z, Mesdaghinia A, Nouri J, Homaee M, Yunesian M, Ahmadimoghaddam M, Mahvi AH (2010) Effect of fertilizer application on soil heavy metal concentration. Environ Monit Assess 160:83-89

4. Bajguz A (2011) Suppression of Chlorella vulgaris Growth by Cadmium, Lead, and Copper Stress and Its Restoration by Endogenous Brassinolide. Arch Environ Contam Toxicol 60:406-416

5. Cai LM, Wang QS, Wen HH, Luo J, Wang S (2019) Heavy metals in agricultural soils from a typical township in Guangdong Province, China: Occurrences and spatial distribution. Ecotoxicol Environ Saf 168:184-191

6. Guo JK, Zhou R, Ren XH, Jia HL, Hua L, Xu HH, Lv X, Zhao J, Wei T (2018) Effects of salicylic acid, Epi-brassinolide and calcium on stress alleviation and Cd accumulation in tomato plants. Ecotoxicol Environ Saf 157:491-496

7. Hasan MM, Uddin MN, Ara-Sharmeen I, H FA, Alzahrani Y, Hakeem KR, Zhang L (2019) :Assisting Phytoremediation of Heavy Metals Using Chemical Amendments. Plants 8

8. Huang C, Zeng GM, Huang DL, Lai C, Xu P, Zhang C, Cheng M, Wan J, Hu L, Zhang Y (2017a) Effect of Phanerochaete chrysosporium inoculation on bacterial community and metal stabilization in lead-contaminated agricultural waste composting. Bioresour Technol 243:294-303

9. Huang DL, Gong XM, Liu YG, Zeng GM, Lai C, Bashir H, Zhou L, Wang DF, Xu PA, Cheng M, Wan J (2017b) Effects of calcium at toxic concentrations of cadmium in plants. Planta 245:863-873

10. Hussain I, Rasheed R, Ashraf MA, Mohsin M, Shah SMA, Rashid DA, Akram M, Nisar J, Riaz M (2020) : Foliar Applied Acetylsalicylic Acid Induced Growth and Key-Biochemical Changes in Chickpea (Cicer arietinum L.) Under Drought Stress. Doseresponse: a publication of International Hormesis Society 18, 1559325820956801

11. Jia HL, Wang XH, Wei T, Wang M, Liu X, Hua L, Ren XH, Guo JK, Li JS (2021) : Exogenous salicylic acid regulates cell wall polysaccharides synthesis and pectin methylation to reduce $\mathrm{Cd}$ accumulation of tomato. Ecotoxicology and environmental safety 207

12. Jin D, Xu Y, Gui H, Zhang H, Dong Q, Sikder RK, Wang X, Yang G, Song M (2020) : Evaluation of Cotton (Gossypium hirsutum L.) Leaf Abscission Sensitivity Triggered by Thidiazuron through Membership Function Value. Plants 10

13. Koleli N, Eker S, Cakmak I (2004) Effect of zinc fertilization on cadmium toxicity in durum and bread wheat grown in zinc-deficient soil. Environ Pollut 131:453-459

14. Kou MZ, Bastias DA, Christensen MJ, Zhong R, Nan ZB, Zhang XX (2021): The Plant Salicylic Acid Signalling Pathway Regulates the Infection of a Biotrophic Pathogen in Grasses Associated with an Epichloe Endophyte.J Fungi7

15. Li B, Zhang C, Cao B, Qin G, Wang W, Tian S (2012) Brassinolide enhances cold stress tolerance of fruit by regulating plasma membrane proteins and lipids. Amino Acids 43:2469-2480

16. Liang Y, Xiao X, Guo Z, Peng C, Zeng P, Wang X (2021) Co-application of indole-3-acetic acid/gibberellin and oxalic acid for phytoextraction of cadmium and lead with Sedum alfredii Hance from contaminated soil. Chemosphere 285:131420

17. Liu Y, Tao Q, Li J, Guo X, Luo J, Jupa R, Liang Y, Li T (2021) Ethylene-mediated apoplastic barriers development involved in cadmium accumulation in root of hyperaccumulator Sedum alfredii. J Hazard Mater 403:123729

18. Lu Q, Chen S, Li Y, Zheng F, He B, Gu M (2020) Exogenous abscisic acid (ABA) promotes cadmium (Cd) accumulation in Sedum alfredii Hance by regulating the expression of Cd stress response genes. Environ Sci Pollut Res Int 27:8719-8731

Page $10 / 20$ 
19. Madany MMY, Obaid WA, Hozien W, AbdElgawad H, Hamed BA, Saleh AM (2020) : Salicylic acid confers resistance against broomrape in tomato through modulation of $\mathrm{C}$ and $\mathrm{N}$ metabolism. Plant physiology and biochemistry: PPB 147, $322-335$

20. Malandrino M, Abollino O, Buoso S, Giacomino A, La Gioia C, Mentasti E (2011) Accumulation of heavy metals from contaminated soil to plants and evaluation of soil remediation by vermiculite. Chemosphere 82:169-178

21. Masood A, Khan MI, Fatma M, Asgher M, Per TS, Khan NA (2016) Involvement of ethylene in gibberellic acid-induced sulfur assimilation, photosynthetic responses, and alleviation of cadmium stress in mustard. Plant physiology and biochemistry: PPB 104:1-10

22. Mesquita VA, Silva CF, Soares EV (2016) Toxicity Induced by a Metal Mixture (Cd, Pb and Zn) in the Yeast Pichia kudriavzevii: The Role of Oxidative Stress. Curr Microbiol 72:545-550

23. Neumann G (2015) The Role of Ethylene in Plant Adaptations for Phosphate Acquisition in Soils - A Review. Front Plant Sci 6:1224

24. Pal M, Ivanovska B, Olah T, Tajti J, Hamow KA, Szalai G, Khalil R, Vankova R, Dobrev P, Misheva SP, Janda T (2019) : Role of polyamines in plant growth regulation of Rht wheat mutants. Plant physiology and biochemistry: PPB / Societe francaise de physiologie vegetale 137, 189-202

25. Pan BG, Mo HQ, Wang W, Cai KZ, Tian JH, Cai YX (2021) Regulating effects of silicon on Cd-accumulation and stress-resistant responding in rice seedling. Ying yong sheng tai xue bao $=$. The journal of applied ecology 32:1096-1104

26. Ramzani PM, Khan WU, Iqbal M, Kausar S, Ali S, Rizwan M, Virk ZA (2016) Effect of different amendments on rice (Oryza sativa L.) growth, yield, nutrient uptake and grain quality in Ni-contaminated soil. Environ Sci Pollut Res Int 23:18585-18595

27. Rostami S, Azhdarpoor A (2019) The application of plant growth regulators to improve phytoremediation of contaminated soils: A review. Chemosphere 220:818-827

28. Saleem M, Asghar HN, Khan MY, Zahir ZA (2015) Gibberellic acid in combination with pressmud enhances the growth of sunflower and stabilizes chromium(VI)-contaminated soil. Environ Sci Pollut Res Int 22:10610-10617

29. Santner A, Estelle M (2009) Recent advances and emerging trends in plant hormone signalling. Nature 459:1071-1078

30. Schubert R, Grunewald S, von Sivers L, Hause B (2019) : Effects of Jasmonate on Ethylene Function during the Development of Tomato Stamens. Plants 8

31. Sharma A, Sidhu GPS, Araniti F, Bali AS, Shahzad B, Tripathi DK, Brestic M, Skalicky M, Landi M (2020) : The Role of Salicylic Acid in Plants Exposed to Heavy Metals. Molecules 25

32. Shu K, Zhou W, Chen F, Luo X, Yang W (2018) Abscisic Acid and Gibberellins Antagonistically Mediate Plant Development and Abiotic Stress Responses. Front Plant Sci 9:416

33. Spence C, Bais H (2015) Role of plant growth regulators as chemical signals in plant-microbe interactions: a double edged sword. Curr Opin Plant Biol 27:52-58

34. Tang H, Liu Y, Gong X, Zeng G, Zheng B, Wang D, Sun Z, Zhou L, Zeng X (2015a) Effects of selenium and silicon on enhancing antioxidative capacity in ramie (Boehmeria nivea (L.) Gaud.) under cadmium stress. Environ Sci Pollut Res Int 22:9999-10008

35. Tang H, Liu YG, Gong XM, Zeng GM, Zheng BH, Wang DF, Sun ZC, Zhou L, Zeng XX (2015b) Effects of selenium and silicon on enhancing antioxidative capacity in ramie (Boehmeria nivea (L.) Gaud.) under cadmium stress. Environ Sci Pollut R 22:999910008

36. Tao Q, Zhao J, Li J, Liu Y, Luo J, Yuan S, Li B, Li Q, Xu Q, Yu X, Huang H, Li T, Wang C (2020) Unique root exudate tartaric acid enhanced cadmium mobilization and uptake in Cd-hyperaccumulator Sedum alfredii. J Hazard Mater 383:121177

37. Ubeda-Tomas S, Swarup R, Coates J, Swarup K, Laplaze L, Beemster GTS, Hedden P, Bhalerao R, Bennett MJ (2008) Root growth in Arabidopsis requires gibberellin/DELLA signalling in the endodermis. Nat Cell Biol 10:625-628

38. Wang FJ, Tan HF, Huang LH, Cai C, Ding YF, Bao H, Chen ZX, Zhu C (2021a) : Application of exogenous salicylic acid reduces Cd toxicity and $\mathrm{Cd}$ accumulation in rice. Ecotoxicology and environmental safety 207

39. Wang JC, Chen XF, Chu SH, Hayat K, Chi YW, Zhi YE, Zhang D, Zhou P (2021b) Influence of Cd toxicity on subcellular distribution, chemical forms, and physiological responses of cell wall components towards short-term Cd stress in Solanum nigrum. Environ Sci Pollut R 28:13955-13969

40. Wang R, Deng H, Jia ZM, Yan MS, Zhou J, Dong JX, Wang JB, Yu F (2021c) [Characteristics of Cadmium Enrichment and Pollution Evaluation of a Soil-Crop System in a Typical Karst Area]. Huan jing ke xue= Huanjing kexue 42:941-951

41. Wang Y, Yuan M, Li Z, Niu Y, Jin Q, Zhu B, Xu Y (2020) Effects of ethylene biosynthesis and signaling on oxidative stress and antioxidant defense system in Nelumbo nucifera G. under cadmium exposure. Environ Sci Pollut Res Int 27:40156-40170

Page 11/20 
42. Wei JL, Lai HY, Chen ZS (2012) Chelator effects on bioconcentration and translocation of cadmium by hyperaccumulators, Tagetes patula and Impatiens walleriana. Ecotoxicol Environ Saf 84:173-178

43. Xia N, Du E, Wu X, Tang Y, Wang Y, de Vries W (2020) Effects of nitrogen addition on soil methane uptake in global forest biomes. Environ Pollut 264:114751

44. Xue D, Jiang H, Deng X, Zhang X, Wang H, Xu X, Hu J, Zeng D, Guo L, Qian Q (2014) Comparative proteomic analysis provides new insights into cadmium accumulation in rice grain under cadmium stress. J Hazard Mater 280:269-278

45. Yadav T, Kumar A, Yadav RK, Yadav G, Kumar R, Kushwaha M (2020) Salicylic acid and thiourea mitigate the salinity and drought stress on physiological traits governing yield in pearl millet- wheat. Saudi J Biol Sci 27:2010-2017

46. Yalpani N, Raskin I (1993) Salicylic acid: a systemic signal in induced plant disease resistance. Trends Microbiol 1:88-92

47. Yan Y, Zhou YQ, Liang CH (2015) : Evaluation of phosphate fertilizers for the immobilization of Cd in contaminated soils.PloS one10, e0124022

48. Yang B, Zhou M, Shu WS, Lan CY, Ye ZH, Qiu RL, Jie YC, Cui GX, Wong MH (2010) Constitutional tolerance to heavy metals of a fiber crop, ramie (Boehmeria nivea), and its potential usage. Environ Pollut 158:551-558

49. Yang Y, Shen Q (2020) Phytoremediation of cadmium-contaminated wetland soil with Typha latifolia L. and the underlying mechanisms involved in the heavy-metal uptake and removal. Environ Sci Pollut Res Int 27:4905-4916

50. Yaseen M, Aziz MZ, Jafar AA, Naveed M, Saleem M (2016) Use of textile waste water along with liquid NPK fertilizer for production of wheat on saline sodic soils. Int J Phytoremediation 18:502-508

51. Yoneyama T, Ishikawa S, Fujimaki S (2015) Route and Regulation of Zinc, Cadmium, and Iron Transport in Rice Plants (Oryza sativa L.) during Vegetative Growth and Grain Filling: Metal Transporters, Metal Speciation, Grain Cd Reduction and Zn and Fe Biofortification. Int J Mol Sci 16:19111-19129

52. Zamani S, Naderi MR, Soleymani A, Nasiri BM (2020) : Sunflower (Helianthus annuus L.) biochemical properties and seed components affected by potassium fertilization under drought conditions. Ecotoxicology and environmental safety 190

53. Zeng GM, Wan J, Huang DL, Hu L, Huang C, Cheng M, Xue WJ, Gong XM, Wang RZ, Jiang DN (2017) Precipitation, adsorption and rhizosphere effect: The mechanisms for Phosphate-induced Pb immobilization in soils-A review. J Hazard Mater 339:354-367

54. Zhang P, Ma YH, Zhang ZY, He X, Li YY, Zhang J, Zheng LR, Zhao YL (2015) Species-specific toxicity of ceria nanoparticles to Lactuca plants. Nanotoxicology 9:1-8

55. Zhao J, Shi GX, Yuan QH (2008) : Polyamines content and physiological and biochemical responses to ladder concentration of nickel stress in Hydrocharis dubia (BI.) Backer leaves. Biometals: an international journal on the role of metal ions in biology, biochemistry, and medicine 21, 665-674

56. Zhao WQ, Dong HR, Zhou ZG, Wang YH, Hu W (2020) Potassium (K) application alleviates the negative effect of drought on cotton fiber strength by sustaining higher sucrose content and carbohydrates conversion rate. Plant Physiol Bioch 157:105-113

57. Zhao XL, Luan MB, Qiu CS, Guo Y, Long SH, Wang YF, Qiu HJ (2021) : Analysis of the potential of 165 ramie germplasms to be used for cadmium-contamination remediation.Ind Crop Prod171

58. Zheng X, Chen L, Li XF (2018) : Arabidopsis and rice showed a distinct pattern in ZIPs genes expression profile in response to Cd stress.Botanical Studies 59

59. Zhu HH, Chen L, Xing W, Ran SM, Wei ZH, Amee M, Wassie M, Niu H, Tang DY, Sun J, Du DY, Yao J, Hou HB, Chen K (2020) : Phytohormones-induced senescence efficiently promotes the transport of cadmium from roots into shoots of plants: A novel strategy for strengthening of phytoremediation.Journal of hazardous materials388

\section{Tables}

Table 1. Concentrations of different plant growth regulators. 


\begin{tabular}{|lll|}
\hline Experiment & Treatments & concentration \\
\hline CK-1 & $0 \mathrm{mg} \mathrm{L}^{-1}$ \\
\hline GA-1 & $50 \mathrm{mg} \mathrm{L}^{-1}$ \\
\hline GA-2 & $100 \mathrm{mg} \mathrm{L}^{-1}$ \\
\hline GA-3 & $200 \mathrm{mg} \mathrm{L}^{-1}$ \\
\hline ETH-1 & $50 \mathrm{mg} \mathrm{L}^{-1}$ \\
\hline ETH-2 & $100 \mathrm{mg} \mathrm{L}^{-1}$ \\
\hline ETH-3 & $200 \mathrm{mg} \mathrm{L}^{-1}$ \\
\hline SA-1 & $50 \mathrm{mg} \mathrm{L}^{-1}$ \\
\hline SA-2 & $100 \mathrm{mg} \mathrm{L}^{-1}$ \\
\hline SA-3 & $200 \mathrm{mg} \mathrm{L}^{-1}$ \\
\hline PAs-1 & $0.1 \mathrm{mmol}^{-1}$ \\
\hline PAs-2 & $1 \mathrm{mmol}^{-1}$ \\
\hline PAs-3 & $10 \mathrm{mmol}^{-1}$ \\
\hline BR-1 & $0.1 \mathrm{mg} \mathrm{L}^{-1}$ \\
\hline BR-2 & $1 \mathrm{mg} \mathrm{L}^{-1}$ \\
\hline BR-3 & $10 \mathrm{mg} \mathrm{L}^{-1}$ \\
\hline
\end{tabular}

Note: GA represents gibberellin, ETH represents ethylene, SA represents salicylic acid, PAs represents polyamine, BR represents Brassinolide, the number 1,2 and 3 indicates the increase of different treatment concentrations, respectively.

Table 2. Concentrations of different plant growth regulator and fertilizers.

\begin{tabular}{|lll|}
\hline Experiment & Treatments & concentration \\
\hline B & CK-2 & $0 \mathrm{mg} \mathrm{L}^{-1}+0 \%$ \\
\cline { 2 - 3 } & $\mathrm{GW}-1$ & $50 \mathrm{mg} \mathrm{L}^{-1}+0 \%$ \\
\hline $\mathrm{GW}-2$ & $100 \mathrm{mg} \mathrm{L}^{-1}+0 \%$ \\
\hline $\mathrm{GW}-3$ & $200 \mathrm{mg} \mathrm{L}^{-1}+0 \%$ \\
\hline $\mathrm{GP}-1$ & $50 \mathrm{mg} \mathrm{L}^{-1}+0.2 \%$ \\
\hline $\mathrm{GP}-2$ & $100 \mathrm{mg} \mathrm{L}^{-1}+0.4 \%$ \\
\hline $\mathrm{GP}-3$ & $200 \mathrm{mg} \mathrm{L}^{-1}+0.6 \%$ \\
\hline $\mathrm{GN}-1$ & $50 \mathrm{mg} \mathrm{L}^{-1}+1 \%$ \\
\hline $\mathrm{GN}-2$ & $100 \mathrm{mg} \mathrm{L}^{-1}+1.5 \%$ \\
\hline $\mathrm{GN}-3$ & $200 \mathrm{mg} \mathrm{L}^{-1}+2 \%$ \\
\hline
\end{tabular}

Note: GW: GA+ Water; GP: GA+ $\mathrm{KH}_{2} \mathrm{PO}_{4} ; \mathrm{GN}: \mathrm{GA}+\mathrm{KNO}_{3}$; The number 1,2 and 3 indicates the increase of different treatment concentrations, respectively. 
Table 3

Agronomic traits and $\mathrm{Cd}$ enrichment of ramie under different hormones

\begin{tabular}{|c|c|c|c|c|c|c|}
\hline Treatments & $\begin{array}{l}\text { Plant height } \\
\text { (cm) }\end{array}$ & $\begin{array}{l}\text { Stem } \\
\text { diameter } \\
(\mathrm{mm})\end{array}$ & $\begin{array}{l}\text { Skin } \\
\text { thickness } \\
(\mathrm{mm})\end{array}$ & $\begin{array}{l}\text { Leaf area } \\
\left(\mathrm{cm}^{2}\right)\end{array}$ & $\begin{array}{l}\text { Biomass } \\
\left(\mathrm{kg} \mathrm{ha}^{-1}\right)\end{array}$ & $\begin{array}{l}\text { Cd enrichment } \\
\left(\mathrm{mg} \mathrm{ha}^{-1}\right)\end{array}$ \\
\hline CK-1 & $212.07 \pm 5.6 \mathrm{DE}$ & $11.45 \pm 0.58 \mathrm{~A}$ & $0.68 \pm 0.01 \mathrm{AB}$ & $228.93 \pm 4.94 \mathrm{AB}$ & $1659.24 \pm 19.09 \mid$ & $22709.46 \pm 70.711$ \\
\hline BR-1 & $215.03 \pm 2.87 \mathrm{DE}$ & $11.02 \pm 1.26 \mathrm{~A}$ & $0.68 \pm 0.06 \mathrm{AB}$ & $230.73 \pm 1.37 A B$ & $2379.69 \pm 72.11 \mathrm{E}$ & $43048.59 \pm 173.46 \mathrm{E}$ \\
\hline BR-2 & $217.30 \pm 5.28 \mathrm{CDE}$ & $10.87 \pm 0.70 \mathrm{~A}$ & $0.71 \pm 0.10 \mathrm{AB}$ & $222.52 \pm 5.11 \mathrm{AB}$ & $2378.18 \pm 79.00 \mathrm{E}$ & $23480.56 \pm 74.83 E$ \\
\hline BR-3 & $221.70 \pm 5.86 \mathrm{BCDE}$ & $11.64 \pm 0.91 \mathrm{~A}$ & $0.74 \pm 0.06 \mathrm{AB}$ & $220.67 \pm 13.82 B$ & $2339.15 \pm 43.59 \mathrm{EF}$ & $34640.09 \pm 71.18 \mathrm{EF}$ \\
\hline ETH-1 & $145.30 \pm 3.82 F$ & $12.94 \pm 0.64 \mathrm{~A}$ & $0.68 \pm 0.04 \mathrm{AB}$ & $183.24 \pm 8.37 \mathrm{C}$ & $1025.15 \pm 8.89 \mathrm{~J}$ & $15824.90 \pm 142.77 \mathrm{~J}$ \\
\hline ETH-2 & $132.05 \pm 2.60 \mathrm{G}$ & $12.39 \pm 1.32 \mathrm{~A}$ & $0.75 \pm 0.12 \mathrm{AB}$ & $159.02 \pm 5.07 \mathrm{D}$ & $965.19 \pm 25.98 \mathrm{~J}$ & $14297.68 \pm 72.57 \mathrm{~J}$ \\
\hline ETH-3 & $132.41 \pm 3.58 G$ & $11.90 \pm 1.06 \mathrm{~A}$ & $0.72 \pm 0.08 \mathrm{AB}$ & $128.65 \pm 3.93 E$ & $1060.80 \pm 88.88 \mathrm{~J}$ & $17588.06 \pm 367.99 \mathrm{~J}$ \\
\hline GA-1 & $212.00 \pm 3.00 \mathrm{DE}$ & $12.10 \pm 0.69 \mathrm{~A}$ & $0.73 \pm 0.11 \mathrm{AB}$ & $161.74 \pm 3.78 \mathrm{D}$ & $1859.60 \pm 46.16 \mathrm{H}$ & $28856.40 \pm 132.63 \mathrm{H}$ \\
\hline GA-2 & $228.00 \pm 4.35 \mathrm{BC}$ & $12.02 \pm 0.75 \mathrm{~A}$ & $0.84 \pm 0.12 \mathrm{~A}$ & $195.03 \pm 7.10 \mathrm{C}$ & $2019.60 \pm 20.52 G$ & $38068.73 \pm 500.58 \mathrm{G}$ \\
\hline GA-3 & $249.33 \pm 4.62 \mathrm{~A}$ & $12.80 \pm 0.60 \mathrm{~A}$ & $0.67 \pm 0.04 \mathrm{AB}$ & $200.62 \pm 9.68 C$ & $2645.83 \pm 109.34 \mathrm{D}$ & $32349.68 \pm 146.97 D$ \\
\hline PAs-1 & $219.73 \pm 1.99 B C D E$ & $11.82 \pm 1.19 \mathrm{~A}$ & $0.69 \pm 0.06 \mathrm{AB}$ & $224.50 \pm 7.87 \mathrm{AB}$ & $2568.07 \pm 90.14 \mathrm{D}$ & $40748.15 \pm 297.18 D$ \\
\hline PAs-2 & $223.27 \pm 1.16 \mathrm{BCD}$ & $12.35 \pm 1.26 \mathrm{~A}$ & $0.70 \pm 0.02 A B$ & $218.02 \pm 5.06 \mathrm{~B}$ & $3304.81 \pm 86.69 \mathrm{~B}$ & $49685.24 \pm 362.86 B$ \\
\hline PAs-3 & $241.87 \pm 0.29 \mathrm{~A}$ & $11.67 \pm 1.17 \mathrm{~A}$ & $0.83 \pm 0.19 \mathrm{~A}$ & $227.30 \pm 12.26 \mathrm{AB}$ & $3980.73 \pm 22.68 \mathrm{~A}$ & $58875.00 \pm 711.80 \mathrm{~A}$ \\
\hline SA-1 & $209.80 \pm 2.33 E$ & $11.43 \pm 1.11 \mathrm{~A}$ & $0.69 \pm 0.07 \mathrm{AB}$ & $220.34 \pm 3.94 B$ & $2209.42 \pm 69.28 \mathrm{~F}$ & $36772.11 \pm 432.05 F$ \\
\hline SA-2 & $220.27 \pm 0.93 B C D E$ & $11.83 \pm 1.50 \mathrm{~A}$ & $0.58 \pm 0.09 \mathrm{~B}$ & $196.79 \pm 6.54 \mathrm{C}$ & $2254.69 \pm 20.00 \mathrm{EF}$ & $21772.79 \pm 285.77 \mathrm{EF}$ \\
\hline SA-3 & $230.03 \pm 13.83 B$ & $11.91 \pm 1.71 \mathrm{~A}$ & $0.80 \pm 0.17 A B$ & $236.02 \pm 5.82 \mathrm{~A}$ & $2827.55 \pm 54.44 \mathrm{C}$ & $35542.30 \pm 216.07 F G$ \\
\hline \multirow[t]{2}{*}{ Treatment } & $P$ & $\mathrm{P}$ & $\mathrm{P}$ & $\mathrm{P}$ & $\mathrm{P}$ & $\mathrm{P}$ \\
\hline & 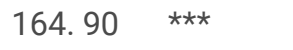 & 0.82 & $\begin{array}{ll}1.35 & 0.23\end{array}$ & 56.18 & $515.02 \quad \star \star \star ~$ & $3284.93 \quad \star \star \star *$ \\
\hline
\end{tabular}


Table 4

Agronomic traits and $\mathrm{Cd}$ enrichment of ramie under different hormones and fertilizers

\begin{tabular}{|c|c|c|c|c|c|c|}
\hline Treatments & $\begin{array}{l}\text { Plant height } \\
\text { (cm) }\end{array}$ & $\begin{array}{l}\text { Stem diameter } \\
(\mathrm{mm})\end{array}$ & $\begin{array}{l}\text { Skin thickness } \\
(\mathrm{mm})\end{array}$ & $\begin{array}{l}\text { Leaf area } \\
\left(\mathrm{cm}^{2}\right)\end{array}$ & $\begin{array}{l}\text { Biomass } \\
\left(\mathrm{kg} \mathrm{ha}^{-1}\right)\end{array}$ & $\begin{array}{l}\text { Cd enrichment } \\
\left(\mathrm{mg} \mathrm{ha}^{-1}\right)\end{array}$ \\
\hline CK-2 & $183.8 \pm 4.44 \mathrm{D}$ & $10.25 \pm 0.40 \mathrm{AB}$ & $0.62 \pm 0.03 \mathrm{~A}$ & $236.04 \pm 3.72 \mathrm{D}$ & $752.62 \pm 12.30 \mathrm{G}$ & $6894.00 \pm 149.52 \mathrm{E}$ \\
\hline GP-1 & 171.2ะ1.97E & $8.73 \pm 0.67 \mathrm{~B}$ & $0.59 \pm 0.07 \mathrm{~A}$ & $201.55 \pm 5.73 E$ & $1005.32 \pm 6.65 F$ & $7144.47 \pm 100.33 E$ \\
\hline GP-2 & $219.3 \pm 3.52 B$ & $11.48 \pm 0.59 \mathrm{~A}$ & $0.74 \pm 0.10 \mathrm{~A}$ & $258.05 \pm 4.41 \mathrm{C}$ & $1336.27 \pm 6.81 \mathrm{D}$ & $11505.28 \pm 818.62 C$ \\
\hline GP-3 & $225.57 \pm 4.55 \mathrm{AB}$ & $12.28 \pm 0.48 \mathrm{~A}$ & $0.66 \pm 0.09 A$ & $272.58 \pm 3.84 \mathrm{AB}$ & $1449.54 \pm 49.46 \mathrm{C}$ & $15198.43 \pm 694.29 B$ \\
\hline GN-1 & $182.68 \pm 3.83 \mathrm{D}$ & $10.38 \pm 0.44 \mathrm{AB}$ & $0.68 \pm 0.10 \mathrm{~A}$ & $224.24 \pm 6.61 \mathrm{D}$ & $1153.65 \pm 45.72 E$ & $8540.86 \pm 224.84 D$ \\
\hline GN-2 & $226.20 \pm 5.00 \mathrm{AB}$ & $12.37 \pm 1.49 \mathrm{~A}$ & $0.73 \pm 0.01 \mathrm{~A}$ & $265.71 \pm 5.69 B C$ & $1398.06 \pm 4.06 \mathrm{CD}$ & $10308.36 \pm 617.67 \mathrm{C}$ \\
\hline GN-3 & $231.43 \pm 3.19 \mathrm{~A}$ & $11.92 \pm 0.39 \mathrm{~A}$ & $0.75 \pm 0.09 \mathrm{~A}$ & $281.76 \pm 7.61 \mathrm{~A}$ & $1456.82 \pm 42.55 \mathrm{C}$ & $15689.95 \pm 34.72 B$ \\
\hline GW-1 & $206.67 \pm 4.38 \mathrm{C}$ & $12.01 \pm 0.53 \mathrm{~A}$ & $0.7 \pm 0.09 A$ & $275.8 \pm 6.57 \mathrm{AB}$ & $1629.20 \pm 81.64 B$ & $15444.82 \pm 867.03 B$ \\
\hline GW-2 & $189.03 \pm 6.83 \mathrm{D}$ & $11.92 \pm 1.47 \mathrm{~A}$ & $0.7 \pm 0.04 \mathrm{~A}$ & $256.23 \pm 3.79 C$ & $2325.11 \pm 49.97 A$ & $19608.43 \pm 48.11 \mathrm{~A}$ \\
\hline GW-3 & $218.00 \pm 2.62 B$ & $10.72 \pm 0.68 \mathrm{AB}$ & $0.56 \pm 0.08 \mathrm{~A}$ & $275.13 \pm 7.71 \mathrm{AB}$ & $1626.20 \pm 31.61 \mathrm{~B}$ & $14240.09 \pm 876.31 B$ \\
\hline \multirow[t]{2}{*}{ Treatment } & $\mathrm{P}$ & $\mathrm{P}$ & $\mathrm{P}$ & $\mathrm{P}$ & $\mathrm{P}$ & $\mathrm{P}$ \\
\hline & $78.27 \quad \star \star \star$ & $6.12 \quad \star \star \star$ & 2.260 .06 & 61.76 & 318.68 & 153.03 \\
\hline
\end{tabular}

Note: The same letters within a column indicate no significant differences $(P>0.01)$ among the treatments and $C K$. Values are means $\pm S D(n=3)$. ***, $P<0.001 ; * \star, P<0.01 ; *, P<0.05$., Duncan's multiple range test.

\section{Figures}




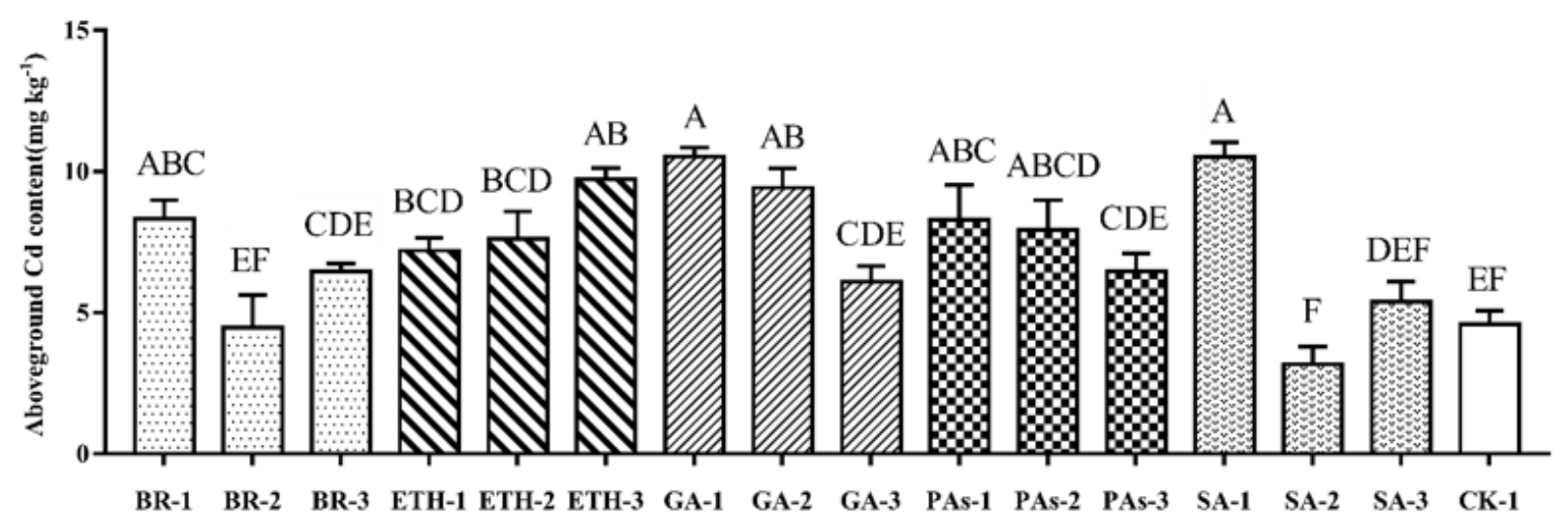

a

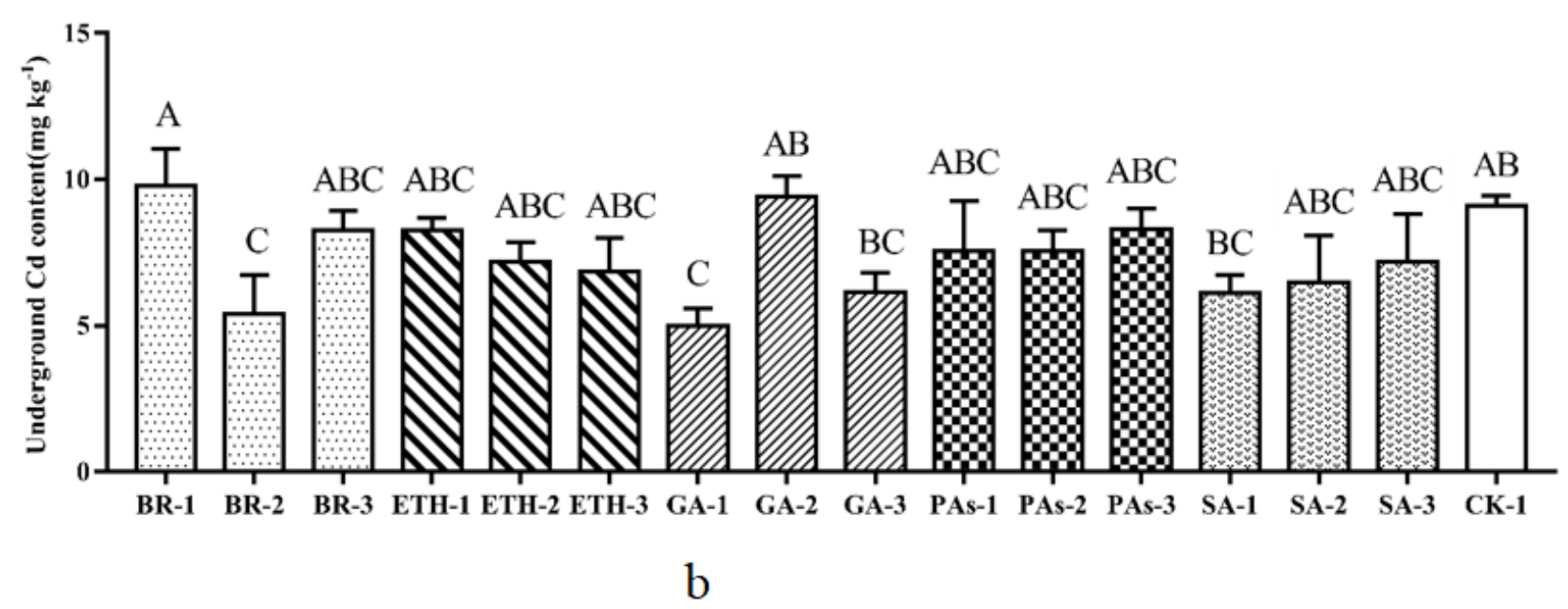

Figure 1

(a) Cd content in aboveground ramie sprayed by plant growth regulators; (b)Cd content in underground ramie sprayed by plant growth regulators; Bars marked with different letters are significantly different among treatments $(P<0.01)$. Values are means $\pm S D(n=3)$. Duncan's multiple range test.

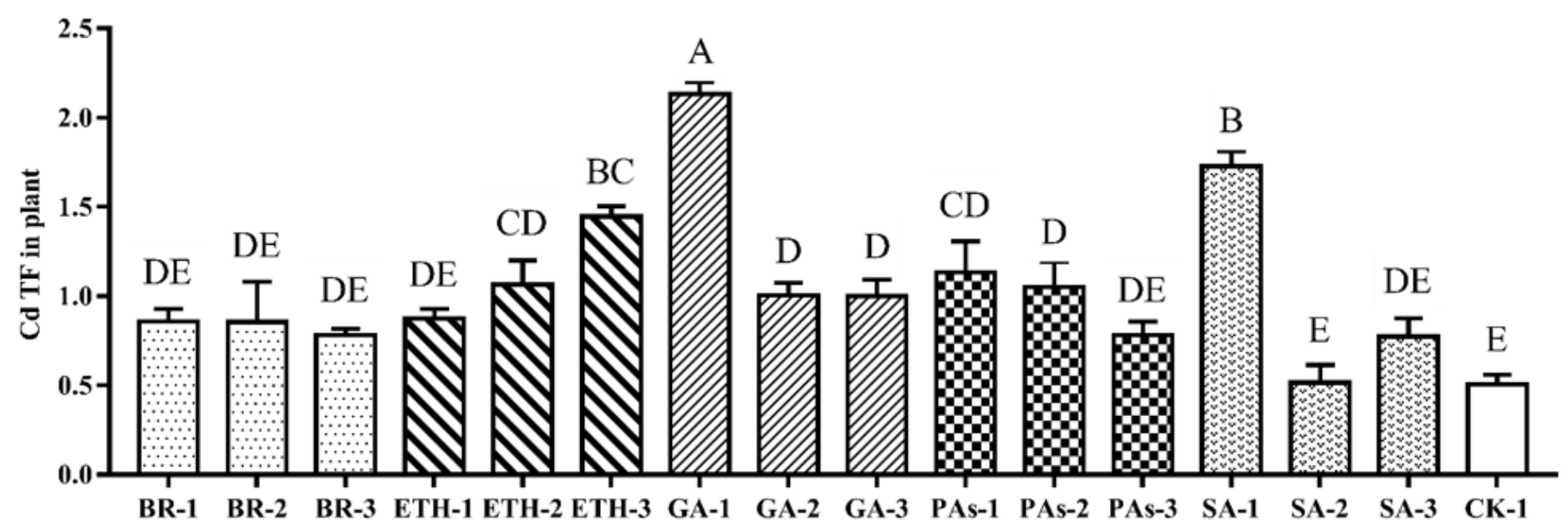

Figure 2 


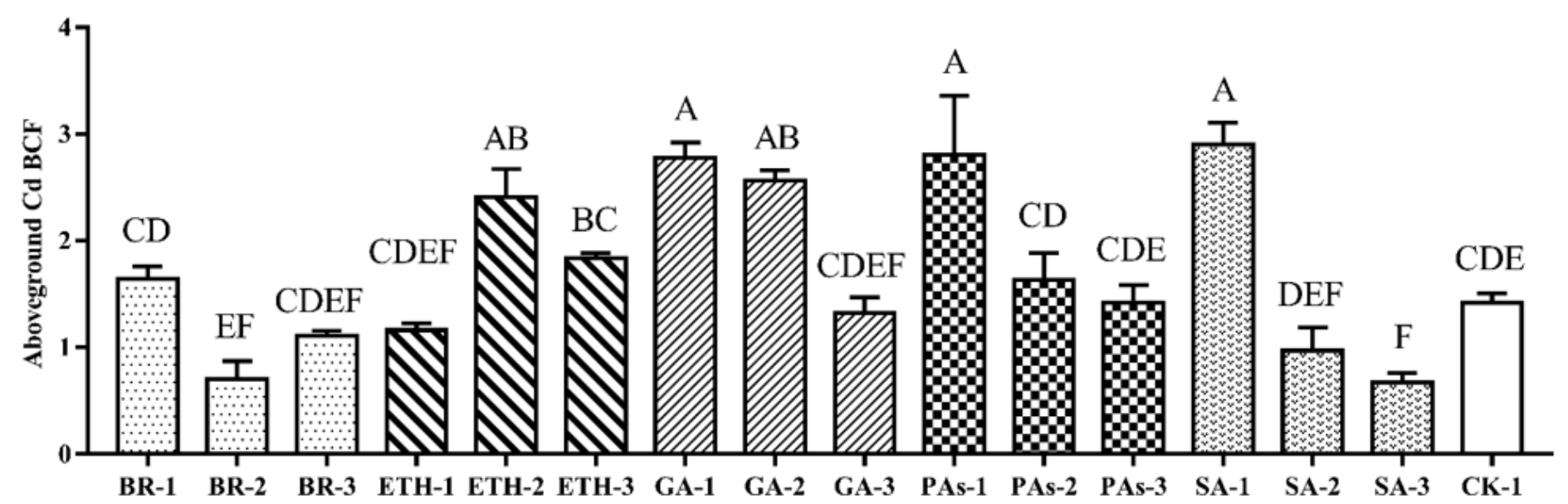

(a)

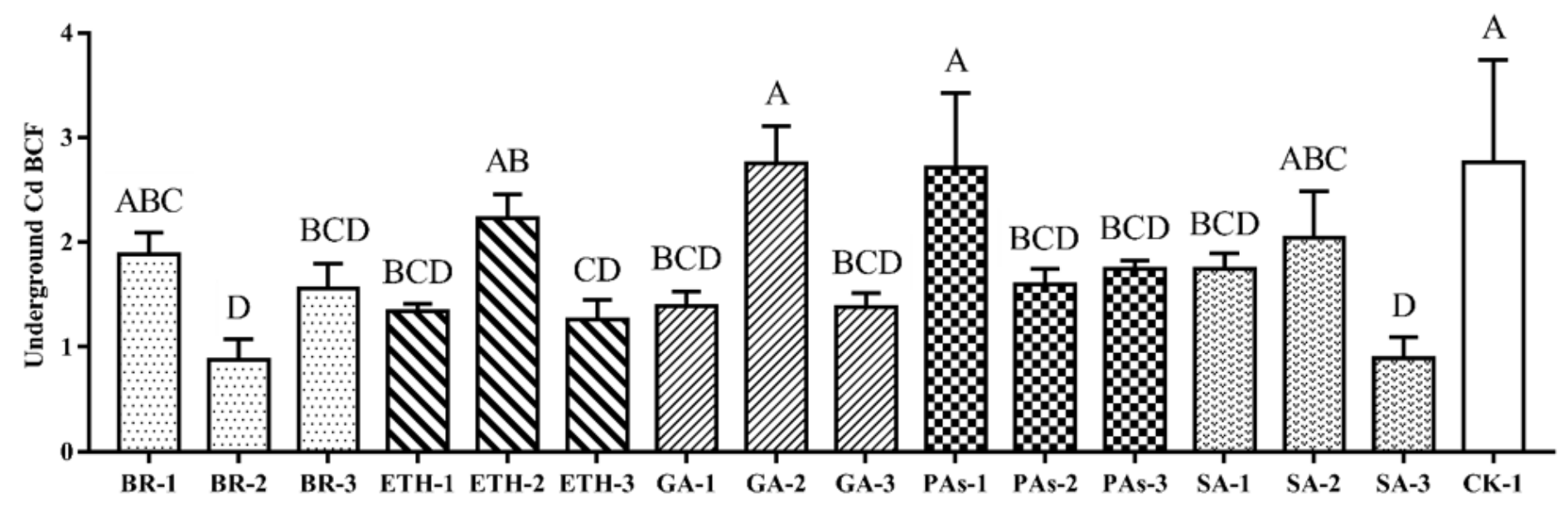

(b)

Figure 3

(a) Cd bioconcentration factors in aboveground ramie sprayed by plant growth regulators; (b)Cd bioconcentration factors in underground ramie sprayed by plant growth regulators; Bars marked with different letters are significantly different among treatments $(P<0.01)$. Values are means $\pm S D(n=3)$. Duncan's multiple range test. 


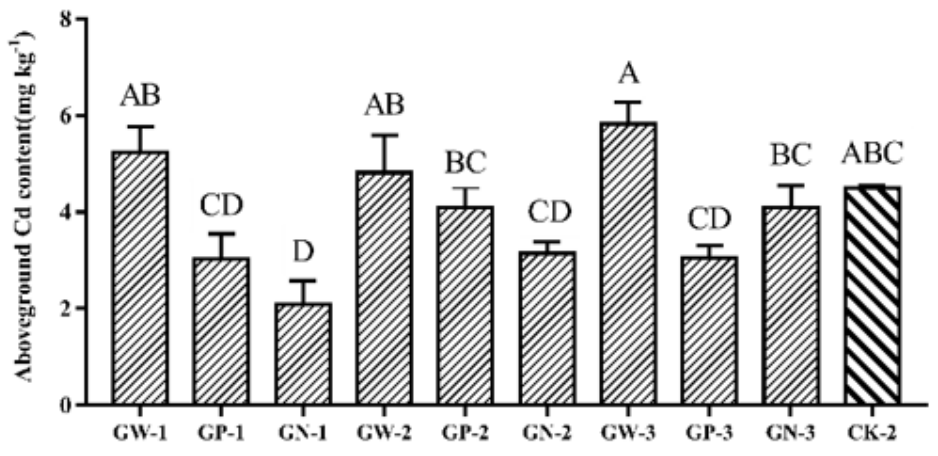

(a)

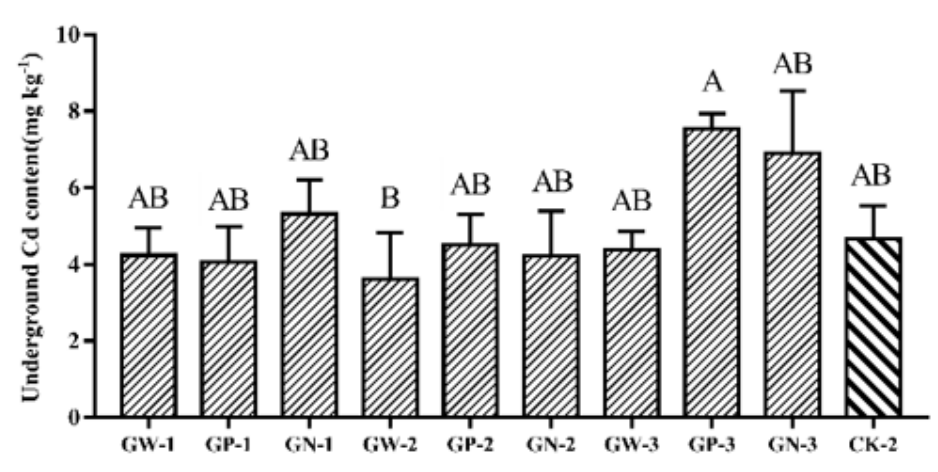

(b)

Figure 4

(a) Cd content in aboveground ramie by spraying mixed plant growth regulator and fertilizers;(b). Cd content in underground ramie by spraying mixed plant growth regulators and fertilizers; Bars marked with different letters are significantly different among treatments $(P$ $<0.01)$. Values are means $\pm S D(n=3)$. Duncan's multiple range test.

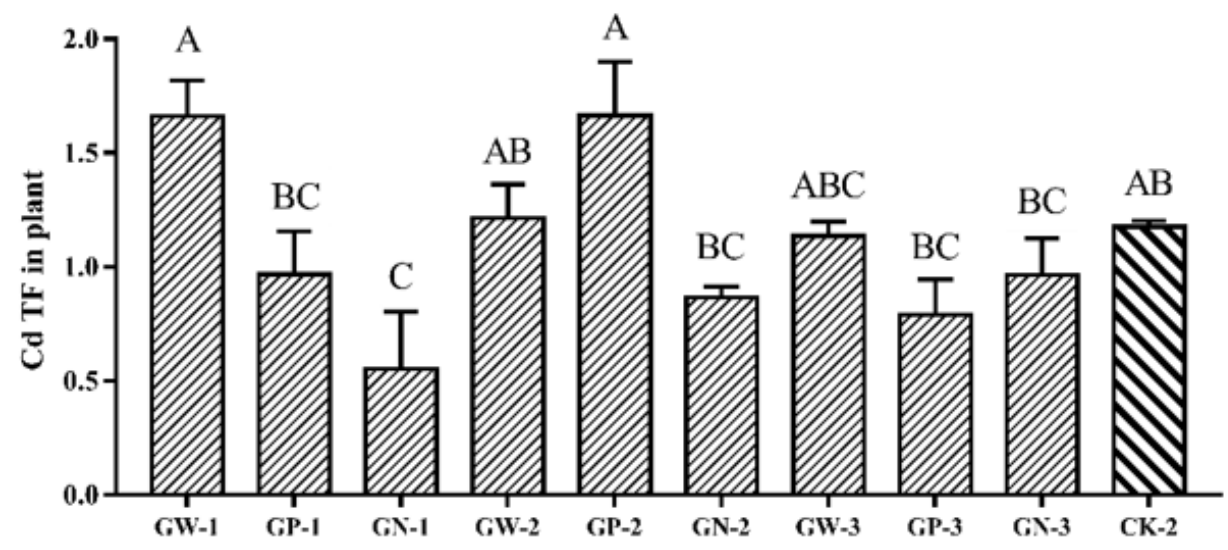

Figure 5

Translocation factors (TFs) from underground to aboveground treated by mixed plant growth regulator and fertilizers; Bars marked with different letters are significantly different among treatments $(P<0.01)$. Values are means $\pm S D(n=3)$. Duncan's multiple range test.

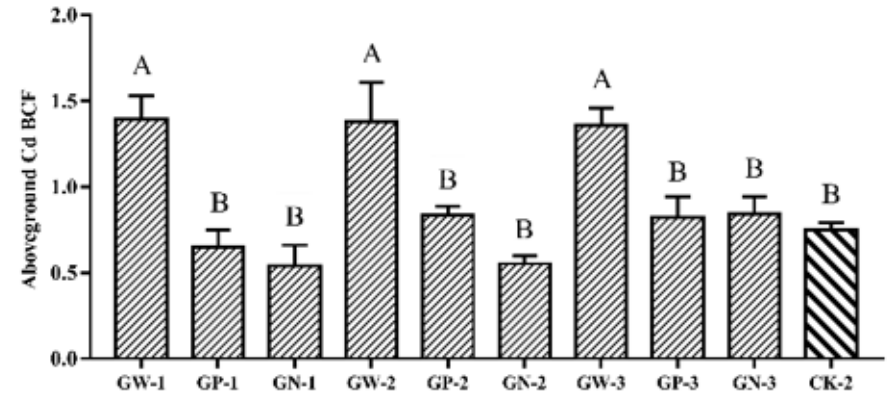

(a)

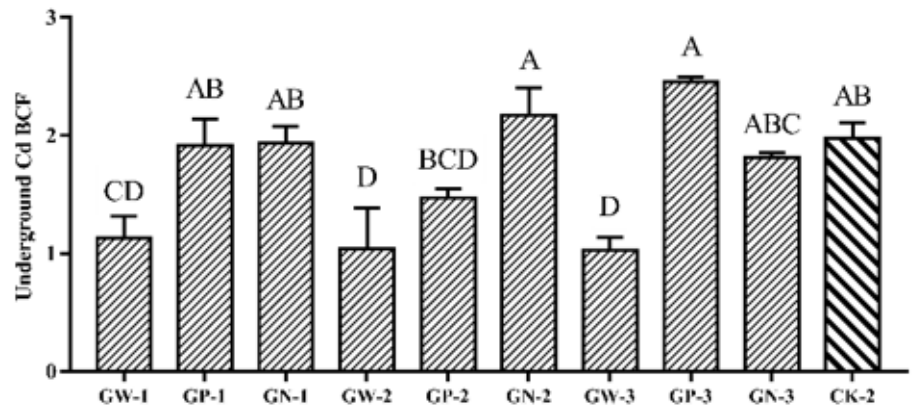

(b)

Figure 6 
(a) Cd bioconcentration factors in aboveground ramie by mixed plant growth regulator and fertilizers;(b). Cd bioconcentration factors in underground ramie by spraying mixed plant growth regulator and fertilizers; Bars marked with different letters are significantly different among treatments $(P<0.01)$. Values are means $\pm S D(n=3)$. Duncan's multiple range test.

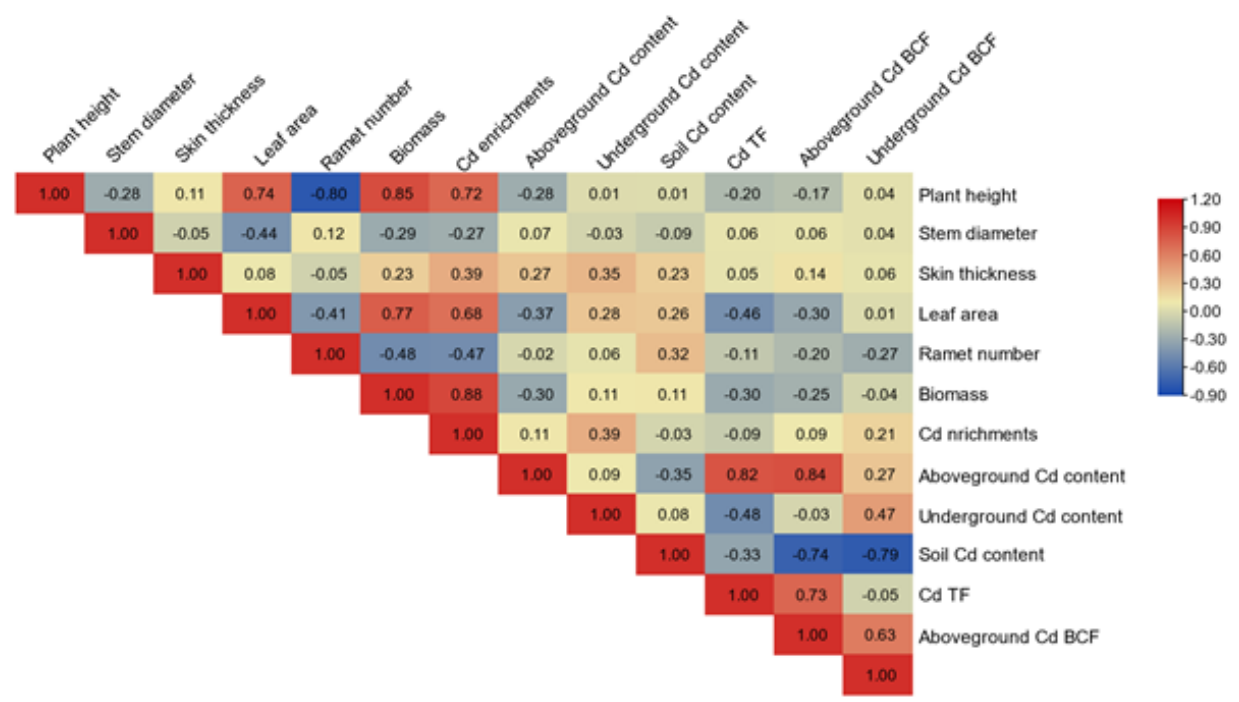

\section{Figure 7}

Correlation index of relevant indicators by plant growth regulators treatments. The shades of the colors and the corresponding numbers represent correlations. The darker the blue, the greater the negative correlation, and the darker the gray, the greater the positive correlation. Pearson's correlation coefficients were used.

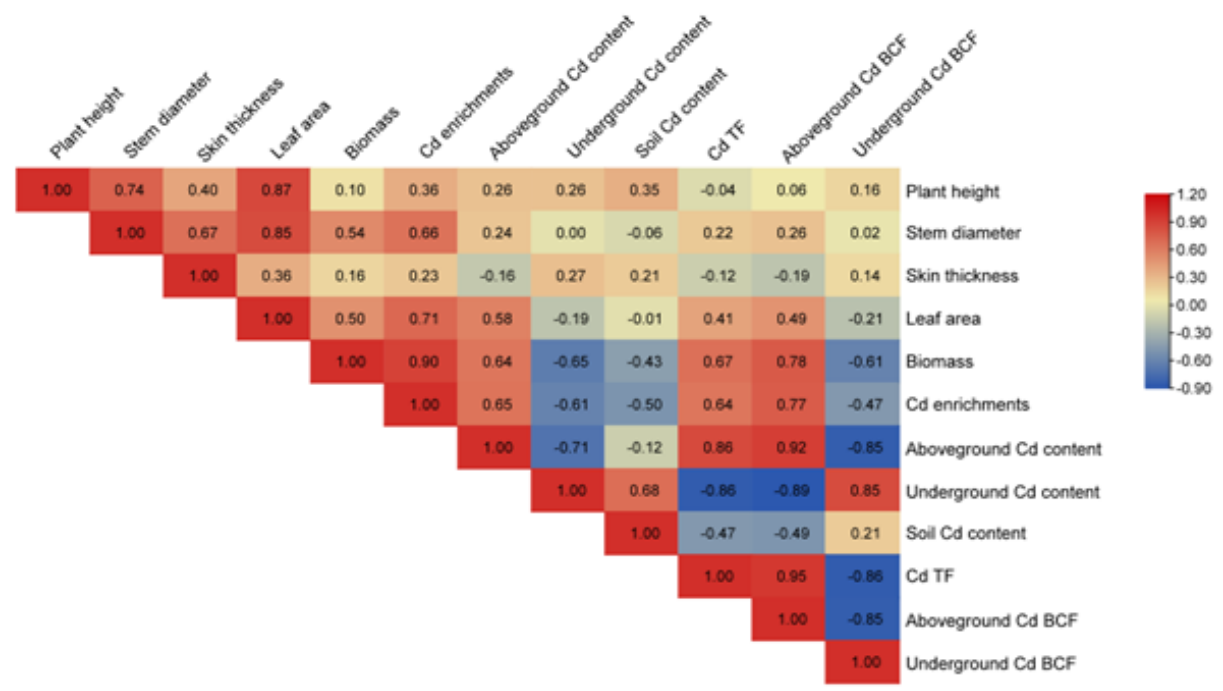

\section{Figure 8}

Correlation index of relevant indicators by mixed plant growth regulator and fertilizers. The shades of the colors and the corresponding numbers represent correlations. The darker the blue, the greater the negative correlation, and the darker the gray, the greater the positive correlation. Pearson's correlation coefficients were used.

\section{Supplementary Files}


This is a list of supplementary files associated with this preprint. Click to download.

- GraphicalAbstract.docx 